\title{
Level and Determinants of Knowledge of Symptomatic Knee Osteoarthritis among Railway Workers in Malaysia
}

\author{
Kurubaran Ganasegeran, ${ }^{1}$ J. Michael Menke, ${ }^{2}$ Vasudeva Murthy Challakere Ramaswamy, ${ }^{3}$ \\ Rizal Abdul Manaf, ${ }^{4}$ Aied M. Alabsi, ${ }^{5}$ and Sami Abdo Radman Al-Dubai ${ }^{6}$ \\ ${ }^{1}$ International Medical School, Management and Science University (MSU), Shah Alam 40100 Selangor, Malaysia \\ ${ }^{2}$ International Medical University (IMU), 57000 Bukit Jalil, Kuala Lumpur, Malaysia \\ ${ }^{3}$ Department of Pathology, International Medical University (IMU), 57000 Bukit Jalil, Kuala Lumpur, Malaysia \\ ${ }^{4}$ Community Health Department, Faculty of Medicine, Universiti Kebangsaan Malaysia (UKM), Cheras, 56000 Kuala Lumpur, \\ Malaysia \\ ${ }^{5}$ Department Oral Biology and Biomedical Science, Faculty of Dentistry, University of Malaya (UM), 50603 Petaling Jaya, Kuala \\ Lumpur, Malaysia \\ ${ }^{6}$ Department of Community Medicine, International Medical University (IMU), 57000 Bukit Jalil, Kuala Lumpur, Malaysia
}

Correspondence should be addressed to Sami Abdo Radman Al-Dubai; samidobaie@yahoo.com

Received 15 August 2013; Revised 14 December 2013; Accepted 7 January 2014; Published 19 February 2014

Academic Editor: Shigeru Kotake

Copyright (C) 2014 Kurubaran Ganasegeran et al. This is an open access article distributed under the Creative Commons Attribution License, which permits unrestricted use, distribution, and reproduction in any medium, provided the original work is properly cited.

Background. Symptomatic knee osteoarthritis, an ancient malady greatly impairing modern population quality of life, has stimulated global attention to find effective modes of prevention and intervention. Purpose. This study aimed to assess factors affecting knowledge of symptomatic knee osteoarthritis (knee OA) among Malaysian railway workers. Methods. A cross-sectional study was conducted among 513 railway workers involving eight major states within Peninsular Malaysia using population-based sampling. The assessment instrument was a face-validated, prepiloted, self-administered instrument with sociodemographics and knowledge items on knee OA. Results. Mean $( \pm S D)$ age of the respondents was $41.4( \pm 10.7)$, with the majority aged 50 years or older (34.9\%). Of the total respondents, $53.6 \%$ had low levels of knowledge of knee OA disease. Multivariate analysis found that four demographic predictors, age $\geq 50$ years, family history of knee OA, self-awareness, and clinical diagnosis of the disease entity, were significantly associated with knowledge scores. Conclusion. The finding of a low level knee OA knowledge among Malaysian railway workers points to an urgent need for massive information to be disseminated among the workers at risk to foster primary prevention and self-care.

\section{Introduction}

Ancient descriptions often referred to musculoskeletal pain and dysfunction as "rheumatism" [1], but paleopathological evidence of excavated skeletons that illustrated degenerative and focal lesions within narrowed joint spaces prompted a more specific and apt term of "osteoarthritis," coined by John Spender in 1886 [2, 3]. Later, OA and associated clinical manifestations were shown to be distinct from rheumatoid arthritis (RA) in pathogenesis and epidemiology [2].

Symptomatic knee OA is currently the fourth leading cause of disability worldwide, [4] with an estimated prevalence of $70-80 \%$ in the population aged 55 years and older
[5]. An ageing Asia with longer lifespan suggests ever-greater numbers of knee OA, among other chronic conditions [6]. The point prevalence of knee OA in Malaysia today is estimated to be $10-20 \%$ of the total adult population [7].

The diagnosis of knee OA lies in both clinical and radiological terms. It is a clinical disease consisting of subjective symptoms of joint pain on loading and bony swelling, objective physical examination of knee stiffness, and deformity or crepitations, along with supplementary radiographic findings $[8,9]$. The Kellgren-Lawrence (K-L) grading scale based on radiographic X-ray has been the standard and acceptable quantification tool to assess knee OA severity [9]. The K-L scoring ranges from 0 to 4 where 0 is normal radiograph; 1 is 
doubtful pathology; 2 is minimal osteophytes with possible narrowing, cysts, and sclerosis; 3 is moderate with definite osteophytes and moderate joint space narrowing; and 4 is severe with large osteophytes and definite joint space narrowing [10]. The grade of $\geq 2$ is classified as osteoarthritis [11].

The Framingham Knee Osteoarthritis Study called knee OA a "disease of the older age" [12]. Disease etiology is multifactorial that includes generalized constitutional (female gender, obesity) $[13,14]$ and hormonal (postmenopausal state) factors $[15,16]$ and local adverse mechanical insults to the knee joint (joint trauma, occupational mechanical loading of the knee joints, and sports and recreational abuse) $[13,14,17$, 18]. Geographical factors like climate change had no predisposition to knee OA [19].

Pathognomonic of knee OA includes significant pain over knee joints associated with varying degrees of functional limitation and reduced quality of life [20]. Other clinical manifestations of knee OA include joint stiffness or numbness with inflammatory signs like swelling, warmth, redness, and crepitus of the knee due to effusions which further exacerbates instability symptoms like "clicking" or "locking" of knee joints causing restricted movement and quadriceps muscle weakness $[13,14,18]$.

A major threat to full employment at older ages is the incapacity arising from symptomatic knee OA [21]. An ageing workforce will contain ever-greater proportion of workers with knee joint pathology [21]. Occupational related activities like walking, sitting, standing, kneeling, squatting, climbing, and heavy lifting and much of self-care will undoubtedly be difficult and uncomfortable with knee OA [21]. Modern research has prompted global economic evaluation as a result of "employment retrenchment," "job absenteeism," "job quitting," "sick leave," "work participation," "work changes," "work adaptations," and "work transitions" due to knee OA functional limitations among workers [22].

A sample of 254 patients with knee OA from Italy reported as $2.4 \%$ for discontinuing work, $2 \%$ changed the type of work, and $22 \%$ with regular knee OA-related sick leave [23]. Similarly, Sayre et al. (2010) [24] investigated "employment reduction" due to OA among subjects from British Columbia and found that $36 \%$ of the subjects with knee OA had quit work entirely and $13 \%$ had reduced working hours.

The OA Research Society International (OARSI) reported that treatments like acetaminophen, nonselective and selective oral nonsteroidal anti-inflammatory drugs (NSAIDs), topical NSAIDs and capsaicin, intra-articular injections of corticosteroids or hyaluronans, glucosamine, and/or chondroitin sulphate may be used for symptom relief, while glucosamine sulphate, chondroitin sulphate, and/or diacerein are administered for structure-modifying effects, and weak opioids or narcotic analgesics are used for the relief of refractory pain [25]. Nonpharmacological management like applying hot or cold compression to the knee joint has been shown to improve knee pain [26-31]. Supportive footwear has been suggested as a preventive measure for knee OA $[30,31]$ and recently was postulated to improve knee loading among knee OA patients [32]. Surgical options like total knee arthroplasty are made available for severe knee OA [17].
Rising prevalence rates and longer lifespan indicate a pending global public health crisis, yet only sparse information for identifying and preparing for it still exists in most developed and developing nations. Despite detailed published accounts of self-management techniques and knee OA prevention, for example, the NICE Guidelines and the Arthritis Foundations' National Public Health Agenda, misconceptions, lack of preventive knowledge, and maladaptive sociocultural beliefs among caregivers and general population in different regions pose substantial barriers towards preventive efforts [33].

To the best of our knowledge, this study was the first population-based study that assessed knowledge of symptomatic knee OA among railway workers. Data on prevalence rates of knee OA among railway workers was rather scarce from both developed and developing countries. Railway workers with diverse occupational traits from both manual and administrative sectors involving locomotive engine pilots or drivers, railroad yardworkers, trackmen, maintenance workers, signalers, station masters, shunters, and office workers were predominantly classified as high strained workers because of their prolonged exposure to rigid protocols and limited rests [34]. Crushed rock ballast covered on railroad yards and tracks creates irregular stance and motions [35]. Railroad yardworkers, shunters, signalers, and trackmen as well as strenuous jobs that demand prolonged improper standing of abnormal stance [18, 35-38], irregular walking postures, kneeling, or squatting postures for railroad track alignments $[39,40]$ were at higher risk of knee OA due increased stresses at the knee joint as a consequence of greater torsional loading on the menisci $[35,41]$. Locomotive engine pilots, train drivers, shunters, and office administrative workers sitting with frequent short length seats in prolonged flexion of the knees suffer increased stress load on the knee joint, prompting an increased risk of knee OA [30].

Occupational health in Malaysia is regulated mainly by the Occupational Safety and Health Act 1994. The responsibilities of safety and health at the workplace lie with those who create the risk and with those who work with the risk. It stresses on self-regulation and participation and cooperation of workers. The Department of Occupational Safety and Health (DOSH) is a department under the Ministry of Human Resources which is responsible for standard setting of relevant legislation and code of practice and guidelines as well as enforcement through the regional branch office in each state in the country [42]. Despite these legislations and guidelines, workplace injuries and occupational health disease that demands increased workers compensation remained high in Malaysia [43]. The "Osteoarthritis Public Health Agenda Policy and Communications White Paper" drafted nine priority policies of urgent tasks [44]. The third priority policy, "increase early access to evidence-based interventions," highlighted the need to promote awareness and knowledge of knee OA among general population and caregivers. As a part of global initiative to foster primary prevention and promote understanding, this study assessed levels of knee OA knowledge in a population of Malaysian railway workers - a population of workers at higher risk of developing knee OA. 


\section{Materials and Methods}

2.1. Ethics Statement. This study complied with the guidelines in the Declaration of Helsinki. Study protocol was approved by the affiliated institutional ethical committee. Following institutional review board, the Cooperative Society Keretapi Tanah Melayu Berhad (KTMB), being representative of all railway workers in Malaysia, granted permission and final approval. Objectives and benefits of the study were explained in written form and attached to the questionnaires for respondent approval. Respondents were assured that information would be confidential and participation would not affect their working status. A written consent was obtained from those who agreed to participate.

2.2. Study Design and Population. This descriptive crosssectional study was conducted in the month of April 2012 among all workers from "Keretapi Tanah Melayu Berhad" (KTMB), the country's largest railway network provider in Peninsular Malaysia. The organization encompassed different job traits (e.g., mechanical, electrical, carpentry, administration, engineering, etc.) comprising of both blue-collar and white-collar workers, therefore making the population being studied representative of the country's main human work force with resources from both skilled and semiskilled sectors. The study recruited all 729 workers registered to the Cooperative Workers Society (KTMB) using population, based sampling involving eight states within Peninsular Malaysia: 294 workers from Kuala Lumpur, 108 from Selangor, 104 from Perak, 91 from Johor, 64 from Kelantan, 30 from Negeri Sembilan, 20 from Kedah, and 18 from Penang. After receiving relevant permissions from the office, we obtained the respondents' postal address. Respondents were approached through a postal survey and were requested to return the completed questionnaires to the Cooperative Workers Society's main office in Kuala Lumpur within a month, after which we recollected all data from the office. Respondents less than 20 years of age were excluded along with those who refused participation.

2.3. Study Instruments. We designed a 36 -item self-administered questionnaire regarding knowledge of knee OA from literatures and proven hypotheses. Validated items on risk factors $[14,16,19,21,30,36,37,39-41,45-47]$, signs and symptoms $[8,13,14,18,48]$, disabilities $[8,14,21]$, and prevention and management $[17,22,26-32]$ extracted from previous studies were conjugated as knowledge scales in the present study. The questionnaire was first piloted among 50 railway workers and slightly modified according to their comments. An expert orthopedic surgeon conducted face validation to ensure the knowledge scale conformed to established knee OA disease criteria. The final questionnaire was comprised of two domains: sociodemographic data and knee OA knowledge. Sociodemographic questions included gender, age, education level, type of occupation, awareness of knee $\mathrm{OA}$ as a disease and signs and symptoms, awareness of any immediate family members with knee $\mathrm{OA}$, and whether the respondent has ever been diagnosed with knee OA. Knowledge was assessed in five subsections: (1) risk factors
(11 items), (2) signs and symptoms (10 items), (3) disabilities (7 items), (4) prevention (4 items), and (5) management (4 items). The questions for each subscale were structured as follows. Regarding knowledge of knee OA, consider the following. (1) Do you think that the following are risk factors of knee OA? (2) Do you know if the following are signs and symptoms of knee OA? (3) Do you think that knee OA causes the following disabilities? (4) Do you think that the following measures help to prevent knee OA? (5) Do you think that the following measures help to relieve knee OA symptoms? Response options were "Yes," "No," and "I do not know." The questionnaire was administered in the local language, Malay.

2.4. Statistical Analysis. Analysis was performed using Statistical Package of Social Sciences (SPSS) (version 16.0, IBM, Armonk, NY). For each item in the knowledge part, the correct answer was coded (1), while the incorrect answer or "I do not know" was coded (0). Scores of knowledge items were summed to obtain the total knowledge score on knee $\mathrm{OA}$ (minimum $=0$ and maximum $=36$ ). A higher score represents better knowledge. A high knowledge level was classified based on median cut-off point of the total score $(\geq 21)$. Descriptive analysis was performed for all variables in this study. Knowledge scores were expressed as mean and standard deviations. Test of normality was performed for the total knowledge score. $t$-test and ANOVA test were applied to compare knowledge across sociodemographic variables. In case of ANOVA, post hoc test was used to determine where the significant difference was. Multiple linear regression analysis using "backward elimination" was employed to obtain significant factors associated with knee OA knowledge. The accepted level of significance was set below $0.05(P<0.05)$. Multicollinearity was checked between independent variables.

\section{Result}

3.1. Sociodemographic Characteristics of Respondents. A total of 513 railway workers with a response rate of $(70.3 \%)$ consented to participate in the survey. The mean $( \pm S D)$ age of respondents was $41.4( \pm 10.7)$ years and the majority aged 50 years or older (34.9\%). The majority of respondents were males $(74.9 \%)$, white-collar workers $(52.0 \%)$, and secondary educated (69.1\%). Less than half (40.2\%) of the entire sample had an immediate family member with the condition. One hundred five (20.5\%) of total respondents reported having knee OA diagnosed clinically by a doctor (Table 1 ).

3.2. Awareness and Knowledge of Knee Osteoarthritis among Respondents. Most of the respondents expressed awareness of knee OA as a disease entity (60.2\%). Based on median cut-off points of knowledge score, $53.6 \%$ of the respondents had low levels of knowledge. Table 2 exhibits individual item scores of knee OA.

\subsection{Association between Knowledge of Knee Osteoarthritis and} Sociodemographic Variables. Table 3 shows the associations between sociodemographic factors and knowledge of knee $\mathrm{OA}$ among respondents. Male respondents displayed higher 
TABLE 1: Sociodemographic characteristics of the respondents $(n=$ 513).

\begin{tabular}{|c|c|c|}
\hline Characteristic & $N$ & $\%$ \\
\hline \multicolumn{3}{|l|}{ Gender } \\
\hline Male & 384 & 74.9 \\
\hline Female & 129 & 25.1 \\
\hline \multicolumn{3}{|c|}{ Age group (years) } \\
\hline $20-34$ & 157 & 30.6 \\
\hline $35-49$ & 177 & 34.5 \\
\hline$\geq 50$ & 179 & 34.9 \\
\hline \multicolumn{3}{|l|}{ Education level } \\
\hline Primary & 11 & 2.1 \\
\hline Secondary & 354 & 69.1 \\
\hline Tertiary & 148 & 28.8 \\
\hline \multicolumn{3}{|l|}{ Occupation } \\
\hline Blue-collar & 246 & 48.0 \\
\hline White-collar & 267 & 52.0 \\
\hline \multicolumn{3}{|c|}{$\begin{array}{l}\text { Awareness of knee } \\
\text { osteoarthritis as a disease } \\
\text { entity }\end{array}$} \\
\hline Yes & 309 & 60.2 \\
\hline No & 204 & 39.8 \\
\hline \multicolumn{3}{|c|}{$\begin{array}{l}\text { Immediate family members } \\
\text { with knee osteoarthritis }\end{array}$} \\
\hline Yes & 207 & 40.4 \\
\hline No & 306 & 59.6 \\
\hline \multicolumn{3}{|c|}{$\begin{array}{l}\text { Diagnosed clinically to have } \\
\text { knee osteoarthritis }\end{array}$} \\
\hline Yes & 105 & 20.5 \\
\hline No & 408 & 79.5 \\
\hline
\end{tabular}

knowledge score $(18.8 \pm 10.5)$ compared to females $(15.0 \pm$ $11.4, P<0.001)$. There was a significant association between age and knowledge $(P<0.001)$; a post hoc test revealed that respondents aged 50 years or more had higher knowledge score $(21.7 \pm 9.1)$ compared to respondents aged $35-49$ years old (18.2 \pm 10.9$)$ and compared to $20-34$ years $(13.3 \pm 10.9 ; P=$ $0.003, P<0.001$, resp.). There was a significant association between education level and knee OA knowledge $(P<0.001)$ and post hoc tests showed that respondents with tertiary education $(20.8 \pm 8.8)$ showed higher knowledge score than those with secondary education $(16.8 \pm 11.5, P<0.001)$. Bluecollar workers exhibited higher knowledge score $(19.8 \pm 10.3)$ than white-collar workers $(16.2 \pm 11.1 ; P<0.001)$. Those respondents aware of knee OA had better overall knowledge score of knee OA $(24.5 \pm 6.2)$ when compared to those generally unaware of the condition $(7.9 \pm 8.5 ; P<0.001)$. Respondents having immediate family members with knee OA had higher knowledge score $(25.5 \pm 5.7)$ compared to respondents without a family history of knee OA (12.8 \pm $10.5 ; P<0.001)$. Respondents who were clinically diagnosed for knee OA showed higher knowledge score $(25.7 \pm 5.6)$ compared to those without such medical condition (15.9 \pm $11.0 ; P<0.001)$.
3.4. Factors Associated with Knowledge of Symptomatic Knee Osteoarthritis among Respondents by Multiple Linear Regression. Table 4 exhibits factors associated with knowledge of knee OA among Malaysian railway workers. Respondents aged 50 years or older had on the average 1.7 (95\% CI 0.13.2) higher score in OA knowledge compared to respondents in the 20-34 age group $(P=0.035)$. Respondents being aware of knee OA had on the average 12.5 (95\% CI 11.0-13.9) higher knowledge score compared to respondents being unaware of the condition $(P<0.001)$. Similarly, respondents with an immediate family member with knee OA averaged a 5.5 (95\% CI 4.1-6.9) higher knowledge score than respondents whose family members did not have the condition $(P<0.001)$. Respondents diagnosed clinically of knee OA averaged 2.06 (95\% CI 0.5-3.7) higher knowledge score in comparison to respondents without knee OA $(P=0.011)$.

\section{Discussion}

4.1. Core Summary Findings. This cross-sectional study was aimed at determining factors affecting knowledge of symptomatic knee OA among Malaysian railway workers. Of the 513 railway men surveyed, $53.6 \%$ reported low levels of knowledge. Our final regression model yielded four variables significantly influencing knee OA knowledge in this group: respondents over 50 years old, respondents previously aware of knee OA, immediate family members with knee OA, and respondents with knee OA diagnosed clinically by a doctor.

4.2. Comparison with Existing Literature. Data on risk factors, clinical manifestations, and available treatment options was well documented in numerous epidemiological studies and clinical trials [6, 49-51]. Our study challenged the current tenets and dogmas that only pathological, radiological, and clinical investigations may elicit awareness and knowledge of symptomatic knee OA. Hypotheses tested in previous studies were conjugated as knowledge scales in the present study to understand the lay population's perception of this disease entity to promote primary prevention. This study was the first to explore knowledge of symptomatic knee OA in the general population, with particular focus among a specific occupational group.

Our sample demonstrated a broad spectrum of preventive knowledge, including self-management techniques for symptomatic relief. A majority reported that avoidance of excessive and prolonged knee weight bearing activities and optimal body weight are the gold standards for prevention. However, the notion that exercise accelerates quadriceps muscle strength and helps to prevent knee OA [52] was less understood in our sample. Respondents in our study agreed that pain killers and anti-inflammatory drugs would prompt symptomatic relief, inconsistent with a recent report from the UK [33].

Female gender and ages greater than 50 years old were at higher risk for developing knee OA [53]. Prevalence of knee $\mathrm{OA}$ was higher among Asian women as compared to Asian men [6]. The Beijing OA study concluded that symptomatic knee OA among Chinese women aged 50 years or older was 2.9 times higher than men [54], suggesting hormonal factors 
TABLE 2: Knowledge of knee osteoarthritis among respondents $(n=513)$.

\begin{tabular}{|c|c|c|}
\hline Statement & Correct answer & $n(\%)$ \\
\hline \multicolumn{3}{|l|}{ Risk factors } \\
\hline Female gender & Yes & $164(32.0)$ \\
\hline Postmenopausal women are more likely to have osteoporosis, not osteoarthritis & No & $346(67.4)$ \\
\hline Age 50 years or older & Yes & $236(46.0)$ \\
\hline Obesity is not a risk factor & No & $303(59.1)$ \\
\hline Previous knee injury & Yes & $325(63.4)$ \\
\hline Sports and leisure time physical activities & Yes & $262(51.1)$ \\
\hline Repetitive strain injury & Yes & $214(41.7)$ \\
\hline Working in a kneeling or squatting position & Yes & $267(52.0)$ \\
\hline Climate change has no risks & Yes & $162(31.6)$ \\
\hline Sitting improperly for long time & Yes & $196(38.2)$ \\
\hline Standing improperly for long time & Yes & $217(42.3)$ \\
\hline \multicolumn{3}{|l|}{ Signs and symptoms } \\
\hline Knee pain & Yes & $370(72.1)$ \\
\hline Stiffness of the knee during the night & No & $265(51.7)$ \\
\hline Feeling of increased warmth in the knee & Yes & $208(40.5)$ \\
\hline Redness of the knee & Yes & $190(37.0)$ \\
\hline "Clicking" or "catching" of the knee & Yes & $256(49.9)$ \\
\hline "Locking" of the knee or unable to fully straighten & Yes & $271(52.8)$ \\
\hline Weakness of muscles of the thigh & Yes & $249(48.5)$ \\
\hline No swelling of the knee & No & $281(54.8)$ \\
\hline Numbness or tingling sensation of the knee & Yes & $232(45.2)$ \\
\hline Pain when touched or pressed the knee & Yes & $272(53.0)$ \\
\hline \multicolumn{3}{|l|}{ Disabilities } \\
\hline Bed ridden rather than difficulty rising from bed & No & $303(59.1)$ \\
\hline Difficulty putting on stockings & Yes & $255(49.7)$ \\
\hline Difficulty rising from sitting & Yes & $328(63.9)$ \\
\hline Difficulty bending to the floor involves osteoarthritis of the hip, not knee & No & $326(63.5)$ \\
\hline Difficulty kneeling & Yes & $334(65.1)$ \\
\hline Difficulty squatting & Yes & $332(64.7)$ \\
\hline Movements are totally impaired & No & $186(36.3)$ \\
\hline \multicolumn{3}{|l|}{ Prevention } \\
\hline Regular exercises & Yes & $255(49.7)$ \\
\hline Optimal body weight is not necessary for prevention & No & $343(66.9)$ \\
\hline Avoiding excessive and prolonged weight bearing to the knees during work & Yes & $347(67.6)$ \\
\hline Supportive footwear & Yes & $222(43.3)$ \\
\hline \multicolumn{3}{|l|}{ Management } \\
\hline Pain killers and anti-inflammatory drugs help to relieve osteoarthritis pain temporarily & Yes & $269(52.4)$ \\
\hline Intra-articular steroid injections help to relieve severe symptoms temporarily & Yes & $212(41.3)$ \\
\hline Knee replacement surgery is indicated for severe osteoarthritis & Yes & $97(18.9)$ \\
\hline Hot or cold packs to the knees help to resolve osteoarthritis symptoms temporarily & Yes & $95(18.5)$ \\
\hline
\end{tabular}

affecting women during menopausal phase accelerates the development of knee OA [55]. Despite greater susceptibility in women, female respondents in this study exhibited significantly lower knowledge of knee OA than their male counterparts. Similarly, this study showed significant differences between age groups with respect to knowledge, with respondents aged over 50 years exhibiting greater understanding of knee OA.

Educational attainment was linked to pain and disability in osteoarthritis [56]; indeed a higher educational level was more predictive for disease progression [57]. Behavioral risks that influenced health-seeking behavior, access, and utilization of health services for early interventions were associated with higher educational level [58]. A higher knowledge of knee OA was found for respondents with tertiary education over those with a primary or secondary education. Andrianakos et al. (2006) [53] found similar findings in the Greek population.

Repetitive strain at tibiofemoral or patellofemoral joints during work is associated with an increased risk of knee OA $[59,60]$. Knee flexion for squatting and kneeling among manual workers are routines, thus predisposing greater risk 
TABLE 3: Association between knowledge of knee osteoarthritis and socio-demographic variables among respondents $(n=513)$.

\begin{tabular}{|c|c|c|}
\hline Characteristic & Mean (SD) & $P$ value \\
\hline \multicolumn{3}{|l|}{ Gender } \\
\hline Male & $18.8(10.5)$ & \\
\hline Female & $15.0(11.4)$ & $<0.001$ \\
\hline \multicolumn{3}{|c|}{ Age group (years) } \\
\hline $20-34$ & $13.3(10.9)$ & \\
\hline $35-49$ & $18.2(10.9)$ & \\
\hline$\geq 50$ & $21.7(9.1)$ & $<0.001$ \\
\hline \multicolumn{3}{|l|}{ Education level } \\
\hline Primary & $13.4(8.3)$ & \\
\hline Secondary & $16.8(11.5)$ & \\
\hline Tertiary & $20.8(8.8)$ & $<0.001$ \\
\hline \multicolumn{3}{|l|}{ Occupation } \\
\hline Blue-collar & $19.8(10.3)$ & \\
\hline White-collar & $16.2(11.1)$ & $<0.001$ \\
\hline \multicolumn{3}{|c|}{$\begin{array}{l}\text { Awareness of knee } \\
\text { osteoarthritis as a disease } \\
\text { entity }\end{array}$} \\
\hline Yes & $24.5(6.2)$ & \\
\hline No & $7.9(8.5)$ & $<0.001$ \\
\hline \multicolumn{3}{|c|}{$\begin{array}{l}\text { Immediate family members } \\
\text { with knee osteoarthritis }\end{array}$} \\
\hline Yes & $25.5(5.7)$ & \\
\hline No & $12.8(10.5)$ & $<0.001$ \\
\hline \multicolumn{3}{|c|}{$\begin{array}{l}\text { Diagnosed clinically to have } \\
\text { knee osteoarthritis }\end{array}$} \\
\hline Yes & $25.7(5.6)$ & \\
\hline No & $15.9(11.0)$ & $<0.001$ \\
\hline
\end{tabular}

TABLE 4: Factors associated with knowledge of symptomatic knee osteoarthritis among respondents by multiple linear regression $(n=513)$.

\begin{tabular}{|c|c|c|c|c|c|c|}
\hline & \multirow{2}{*}{ B } & \multirow{2}{*}{ SE } & \multirow{2}{*}{ Beta } & \multirow{2}{*}{$P$ value } & \multicolumn{2}{|c|}{$95 \% \mathrm{CI}$} \\
\hline & & & & & Lower & Upper \\
\hline Age (35-49 years) & 1.3 & 0.7 & 0.1 & 0.078 & -0.1 & 2.8 \\
\hline Age ( $\geq 50$ years) & 1.7 & 0.8 & 0.1 & 0.035 & 0.1 & 3.2 \\
\hline Education (tertiary) & 1.3 & 0.7 & 0.1 & 0.056 & 0.0 & 2.6 \\
\hline Type of work (blue-collar) & 1.0 & 0.6 & 0.1 & 0.083 & -0.1 & 2.2 \\
\hline $\begin{array}{l}\text { Awareness of knee osteoarthritis as a disease } \\
\text { entity }\end{array}$ & 12.5 & 0.7 & 0.6 & $<0.001$ & 11.0 & 13.9 \\
\hline $\begin{array}{l}\text { Having family members with knee } \\
\text { osteoarthritis }\end{array}$ & 5.5 & 0.7 & 0.2 & $<0.001$ & 4.1 & 6.9 \\
\hline $\begin{array}{l}\text { Diagnosed clinically to have knee } \\
\text { osteoarthritis }\end{array}$ & 2.1 & 0.8 & 0.1 & 0.011 & 0.5 & 3.7 \\
\hline
\end{tabular}

*The reference group for gender is "female"; for age is "20-34 years"; for education level is "primary"; for occupation is "white-collar"; for all other variables is "no."

${ }^{* *}$ B: unstandardized coefficients, SE: standard error, Beta: standardized coefficients, CI: confidence intervals.

for development of symptomatic knee OA [61, 62]. Prevalence rates corresponded with knee OA knowledge. This study found significant association between knowledge of knee OA and occupational level, albeit blue-collar workers portrayed higher knowledge than white-collar workers.
Family history reflects a higher genetic susceptibility and shares environmental or behavioral factors of disease [63]. Knee OA was less likely to be genetically inherited, but more likely to be caused by shared environmental factors [64]. Not surprisingly, the respondents who had immediate 
family members with symptomatic knee OA exhibited higher knowledge than those without family history. In addition, respondents being aware of knee OA or have been clinically diagnosed for the disease exhibited a significantly higher knowledge level of the disease. Higher knowledge in families that has been explained [65] by family member experiences of a disease induces feelings of vulnerability through vicarious learning. From the results above, it may be inferred that inculcating awareness through public health education is an important primary preventive tool to increase knowledge of knee OA disease. Higher knowledge level among workers with knee OA or those with a family history of knee OA in comparison to workers without disease exposure indicates that education is a typical way to increase the awareness of a particular disease.

4.3. Study Limitations. The following limitations should be acknowledged in this study. This is the first population-based study to measure and self-report knowledge of symptomatic knee OA among workers. Exclusive reliance upon knowledge scales used here may pose correlation inflations. The crosssectional nature of this study could not establish the causal relationships. The issue of measurement variation could be another limitation in this study.

4.4. Implications and Future Direction. This study initiated in-depth insights of symptomatic knee OA knowledge among the general population, stimulating a national public health agenda for prevention of knee OA and related problems. Access to information, education, and social support is vital [66]. Behavioral modification techniques combined with education facilitate self-efficacy of knee OA [67]. Policies for preventive efforts might be implemented in community health settings and major health care facilities around the country.

\section{Conclusion}

The results from this cross-sectional study impact important public health decisions, given that respondents over 50 years, with a family history, self-awareness, and a knee OA diagnosis, showed better knowledge of symptomatic knee OA as shown in the multivariate analysis. In general, Malaysian railway workers projected low levels of knowledge regarding symptomatic knee OA, demonstrating an alarming ignorance on the subject, suggesting the need for more and better information to be disseminated among the railway workers.

\section{Abbreviations}

OA: Osteoarthritis

RA: Rheumatoid arthritis

SD: Standard deviation.

\section{Conflict of Interests}

The authors declare that there is no conflict of interests regarding the publication of this paper.

\section{Acknowledgments}

The authors of this study expressed their sincere gratitude to Mr. Mohamed Faid Bin Musa, President of Cooperative Society, Keretapi Tanah Melayu Berhad (KTMB), for his support and approval of the study to be conducted among Malaysian railway workers. They thank all railway workers who participated in this study, without whom the valuable information elicited in this study would not be available.

\section{References}

[1] L. C. Parish, "An historical approach to the nomenclature of rheumatoid arthritis," Arthritis and rheumatism, vol. 6, pp. 138158, 1963.

[2] O. Sangha, "Epidemiology of rheumatic diseases," Rheumatology, vol. 39, no. 2, pp. 3-12, 2000.

[3] K. Inoue, S. Hukuda, P. Fardellon et al., "Prevalence of largejoint osteoarthritis in Asian and Caucasians skeletal populations," Rheumatology, vol. 40, no. 1, pp. 70-73, 2001.

[4] M. Fransen, L. Bridgett, L. March, D. Hoy, E. Penserga, and P. Brooks, "The epidemiology of osteoarthritis in Asia," International Journal of Rheumatic Diseases, vol. 14, no. 2, pp. 113-121, 2011.

[5] K. O. Enohumah and C. O. Imarengiaye, "Pain in osteoarthritis," African Journal Biomedical Research, vol. 11, no. 2, pp. 119-128, 2008.

[6] I. Kim, H. A. Kim, Y.-I. Seo et al., “Tibiofemoral osteoarthritis affects quality of life and function in elderly Koreans, with women more adversely affected than men," BMC Musculoskeletal Disorders, vol. 11, article 129, 2010.

[7] Clinical Practice Guidelines on the Management of Osteoarthritis, Ministry of Health Malaysia, 2010.

[8] E. Z. Gonzales-Penserga, "Disease mechanisms in osteoarthritis," Philippine Journal of Internal Medicine, vol. 47, pp. 231-235, 2009.

[9] B.-C. An, K. Fang, Y. Wang, Y.-M. Zeng, and K.-R. Dai, "New variables for measuring joint space width to evaluate knee osteoarthritis," Chinese Medical Journal, vol. 124, no. 23, pp. 3886-3890, 2011.

[10] J. H. Kellgren and J. S. Lawrence, "Radiological assessment of osteo-arthrosis," Annals of the Rheumatic Diseases, vol. 16, no. 4, pp. 494-502, 1957.

[11] R. D. Altman, "Criteria for classification of clinical osteoarthritis," Journal of Rheumatology, vol. 18, no. 27, pp. 10-12, 1991.

[12] D. T. Felson, Y. Zhang, J. M. Anthony, A. Naimark, and J. J. Anderson, "Weight loss reduces the risk for symptomatic knee osteoarthritis in women: the Framingham Study," Annals of Internal Medicine, vol. 116, no. 7, pp. 535-539, 1992.

[13] G. Peat, R. C. Duncan, L. R. J. Wood, E. Thomas, and S. Muller, "Clinical features of symptomatic patellofemoral joint osteoarthritis," Arthritis Research and Therapy, vol. 14, no. 2, article R63, 2012.

[14] N. Usman and S. Nuhmani, "Osteoarthritis of knee-a review of current concepts," Middle East Journal of Age and Ageing, vol. 10, pp. 38-42, 2013.

[15] D. von Mühlen, D. Morton, C. A. von Mühlen, and E. BarrettConnor, "Postmenopausal estrogen and increased risk of clinical osteoarthritis at the hip, hand, and knee in older women," Journal of Women's Health and Gender-Based Medicine, vol. 11, no. 6, pp. 511-518, 2002. 
[16] A. Mahajan, V. Tandon, S. Verma, and S. Sharma, "Osteoarthritis and menopause," Journal of Indian Rheumatology Association, vol. 13, pp. 21-25, 2005.

[17] K. Ronn, N. Reischl, E. Gautier, and M. Jacobi, "Current surgical treatment of knee osteoarthritis," Arthritis, vol. 2011, Article ID 454873, 9 pages, 2011.

[18] K. K. W. Chan and L. W. Y. Chan, "A qualitative study on patients with knee osteoarthritis to evaluate the influence of different pain patterns on patients' quality of life and to find out patients' interpretation and coping strategies for the disease," Rheumatology Reports, vol. 3, no. 1, pp. 9-15, 2011.

[19] F. V. Wilder, B. J. Hall, and J. P. Barrett, "Osteoarthritis pain and weather," Rheumatology, vol. 42, no. 8, pp. 955-958, 2003.

[20] National Institute for Health \& Clinical Excellence-Osteoarthritis: The care and management of osteoarthritis in adults, NICE Clinical Guideline, vol. 59, 2008.

[21] K. T. Palmer, "The older worker with osteoarthritis of the knee," British Medical Bulletin, vol. 102, pp. 79-88, 2012.

[22] H. J. Bieleman, S. M. A. Bierma-Zeinstra, F. G. J. Oosterveld, M. F. Reneman, A. P. Verhagen, and J. W. Groothoff, "The effect of osteoarthritis of the hip or knee on work participation," Journal of Rheumatology, vol. 38, no. 9, pp. 1835-1843, 2011.

[23] G. Leardini, F. Salaffi, R. Caporali, B. Canesi, L. Rovati, and R. Montanelli, "Direct and indirect costs of osteoarthritis of the knee," Clinical and Experimental Rheumatology, vol. 22, no. 6, pp. 699-706, 2004.

[24] E. C. Sayre, L. C. Li, J. A. Kopec, J. M. Esdaile, S. Bar, and J. Cibere, "The effect of disease site (knee, hip, hand, foot, lower back or neck) on employment reduction due to osteoarthritis," PLoS ONE, vol. 5, no. 5, Article ID e10470, 2010.

[25] W. Zhang, G. Nuki, R. W. Moskowitz et al., "OARSI recommendations for the management of hip and knee osteoarthritis. Part III: changes in evidence following systematic cumulative update of research published through January 2009," Osteoarthritis and Cartilage, vol. 18, no. 4, pp. 476-499, 2010.

[26] F. G. J. Oosterveld and J. J. Rasker, "Treating arthritis with locally applied heat or cold," Seminars in Arthritis and Rheumatism, vol. 24, no. 2, pp. 82-90, 1994.

[27] L. Brosseau, K. A. Yonge, V. Robinson et al., "Thermotherapy for treatment of osteoarthritis," Cochrane Database of Systematic Reviews, vol. 4, Article ID CDO04522, 2003.

[28] M. Doherty, P. Lanyon, and G. Hosie, "Osteoarthritis of the knee and hip-collected reports on the rheumatic diseases," Arthritis Research Campaign, vol. 4, pp. 89-94, 2005.

[29] M. Porcheret, K. Jordan, and C. Jinks, "Primary care treatment of knee pain-a survey in older adults," Rheumatology, vol. 46, no. 11, pp. 1694-1700, 2007.

[30] Arthritis Info No 1, "Practical tips for osteoarthritis of the knee," American Arthritis Society, 2010, http://www.americanarthritis.org/portal/loader.php?seite=practical_tips_for_knee_oa.

[31] The National Collaborating Centre for Chronic Conditions, Osteoarthritis-National Clinical Guideline For Care and Management in Adults, Royal College of Physicians, 2008.

[32] N. Shakoor, R. H. Lidtke, M. A. Wimmer et al., "Improvement in knee loading after use of specialized footwear for knee osteoarthritis: results of a six-month pilot investigation," Arthritis \& Rheumatology, vol. 65, no. 5, pp. 1282-1289, 2013.

[33] F. Ali, C. Jinks, and B. N. Ong, "Keep mobile, I think that's half the battle: a qualitative study of prevention of knee pain in symptomless older adults," BMC Public Health, vol. 12, p. 753, 2012.
[34] D. Kumar, J. V. Singh, and P. S. Kharwar, "Study of occupational stress among railway engine pilots," Indian Journal of Occupational and Environmental Medicine, vol. 15, no. 1, pp. 25-28, 2011.

[35] A. S. Merryweather, Lower Limb Biomechanics of Walking on Slanted and Level Railroad Ballast, ProQuest, 2008.

[36] M. H. Pope, H. Broman, and T. Hansson, "Impact response of the standing subject-a feasibility study," Clinical Biomechanics, vol. 4, no. 4, pp. 195-200, 1989.

[37] M. L. Magnusson and M. H. Pope, "A review of the biomechanics and epidemiology of working postures," Journal of Sound and Vibration, vol. 215, no. 4, pp. 965-976, 1998.

[38] K. D. Allen, J.-C. Chen, L. F. Callahan et al., "Associations of occupational tasks with knee and hip osteoarthritis: The Johnston County Osteoarthritis Project," Journal of Rheumatology, vol. 37, no. 4, pp. 842-850, 2010.

[39] National Standard for Health Assessment of Rail Safety Workers, Management Systems-Incorporating the Guideline for Health Risk Management, vol. 1, National Transport Communication of Australia, 2004.

[40] Office of Research and Development, Human Factors in Railroad Operations-Communication and Coordination Demands of Railroad Roadway Worker Activities and Implications for New Technology, US Department of Transportation, 2007.

[41] R. O. Andres, K. G. Holt, and M. Kubo, "Impact of railroad ballast type on frontal plane ankle kinematics during walking," Applied Ergonomics, vol. 36, no. 5, pp. 529-534, 2005.

[42] Department of Occupational Safety and Health (DOSH), "Occupational Safety and Health Act 1994," Ministry of Human Resources Malaysia, 2013, http://www.dosh.gov.my/index.php? lang=en.

[43] Social Security Organisation and Ministry of Human Resources Malaysia, 2013, http://www.perkeso.gov.my/en.html.

[44] "Osteoarthritis Public Health Agenda: Policy and Communications White Paper," Center for Disease Control (CDC) \& Arthritis Foundation's National Public Health Agenda, 2008.

[45] T. E. Bernard, F. V. Wilder, M. Aluoch, and P. E. Leaverton, "Jobrelated osteoarthritis of the knee, foot, hand, and cervical spine," Journal of Occupational and Environmental Medicine, vol. 52, no. 1, pp. 33-38, 2010.

[46] D. Botje, I. Zoer, M. M. Ruitenburg, M. H. W. Frings-Dresen, and J. K. Sluiter, "On-site observations of physical work demands of train conductors and service electricians in the Netherlands," Ergonomics, vol. 53, no. 8, pp. 1016-1023, 2010.

[47] B. Heidari, "Knee osteoarthritis prevalence, risk factors, pathogenesis and features: part I," Caspian Journal of Internal Medicine, vol. 2, no. 2, pp. 205-212, 2011.

[48] J. R. Hochman, M. R. French, S. L. Bermingham, and G. A. Hawker, "The nerve of osteoarthritis pain," Arthritis Care and Research, vol. 62, no. 7, pp. 1019-1023, 2010.

[49] V. B. Kraus, "Pathogenesis and treatment of osteoarthritis," Medical Clinics of North America, vol. 81, no. 1, pp. 85-112, 1997.

[50] M. E. Hale, R. Fleischmann, R. Salzman et al., "Efficacy and safety of controlled-release versus immediate-release oxycodone: randomized, double-blind evaluation in patients with chronic back pain," Clinical Journal of Pain, vol. 15, no. 3, pp. 179-183, 1999.

[51] S. Rytter, N. Egund, L. K. Jensen, and J. P. Bonde, “Occupational kneeling and radiographic tibiofemoral and patellofemoral osteoarthritis," Journal of Occupational Medicine and Toxicology, vol. 4, no. 1, article 19, 2009. 
[52] T. A. Scerpella, J. N. Dowthwaite, and P. F. Rosenbaum, "Sustained skeletal benefit from childhood mechanical loading," Osteoporosis International, vol. 22, no. 7, pp. 2205-2210, 2011.

[53] A. A. Andrianakos, L. K. Kontelis, D. G. Karamitsos et al., "Prevalence of symptomatic knee, hand, and hip osteoarthritis in Greece. The ESORDIG study," Journal of Rheumatology, vol. 33, no. 12, pp. 2507-2514, 2006.

[54] Y. Zhang, L. Xu, and M. C. Nevitt, "Comparison of the prevalence of knee osteoarthritis between the elderly Chinese population in Beijing and whites in the United States: The Beijing Osteoarthritis Study," Arthritis \& Rheumatology, vol. 44, pp. 2065-2071, 2001.

[55] A. E. Wluka, F. M. Cicuttini, and T. D. Spector, "Menopause, oestrogens and arthritis," Maturitas, vol. 35, no. 3, pp. 183-199, 2000.

[56] P. Creamer, M. Lethbridge-Cejku, and M. C. Hochberg, "Factors associated with functional impairment in symptomatic knee osteoarthritis," Rheumatology, vol. 39, no. 5, pp. 490-496, 2000.

[57] J. P. Leigh and J. F. Fries, "Mortality predictors among 263 patients with rheumatoid arthritis," Journal of Rheumatology, vol. 18, no. 9, pp. 1307-1312, 1991.

[58] E. M. Badley and D. Ibanez, "Socioeconomic risk factors and musculoskeletal disability," Journal of Rheumatology, vol. 21, no. 3, pp. 515-522, 1994.

[59] Y. Zhang and J. M. Jordan, "Epidemiology of osteoarthritis," Clinics in Geriatric Medicine, vol. 26, no. 3, pp. 355-369, 2010.

[60] A. Klussmann, H. Gebhardt, and M. Nubling, "Individual and occupational risk factors for knee osteoarthritis: results of a case-control study in Germany," Res Ther, vol. 12, article r88, 2010.

[61] D. T. Felson, M. T. Hannan, A. Naimark et al., "Occupational physical demands, knee bending, and knee osteoarthritis: results from the Framingham Study," Journal of Rheumatology, vol. 18, no. 10, pp. 1587-1592, 1991.

[62] D. Coggon, P. Croft, S. Kellingray, D. Barrett, M. McLaren, and C. Cooper, "Occupational physical activities and osteoarthritis of the knee," Arthritis \& Rheumatology, vol. 43, pp. 1443-1449, 2000.

[63] L. Claassen, L. Henneman, A. C. J. Janssens et al., "Using family history information to promote healthy lifestyles and prevent diseases; A discussion of the evidence," BMC Public Health, vol. 10, article 248, 2010.

[64] D. T. Felson and Y. Zhang, "An update on the epidemiology of knee and hip osteoarthritis with a view to prevention," Arthritis \& Rheumatology, vol. 41, pp. 1343-1355, 1998.

[65] R. Schwarzer, "Optimism, vulnerability, and self-beliefs as health-related cognitions: a systematic overview," Psychology \& Health, vol. 9, pp. 161-180, 1994.

[66] P. Dieppe and K. D. Brandt, "What is important in treating osteoarthritis? Whom should we treat and how should we treat them?" Rheumatic Disease Clinics of North America, vol. 29, no. 4, pp. 687-716, 2003.

[67] K. R. Lorig and H. R. Holman, "Self-management education: history, definition, outcomes, and mechanisms," Annals of Behavioral Medicine, vol. 26, no. 1, pp. 1-7, 2003. 


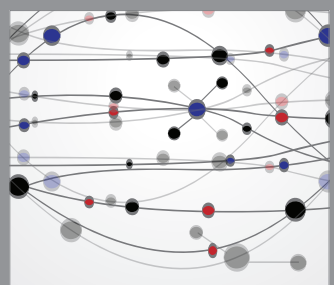

The Scientific World Journal
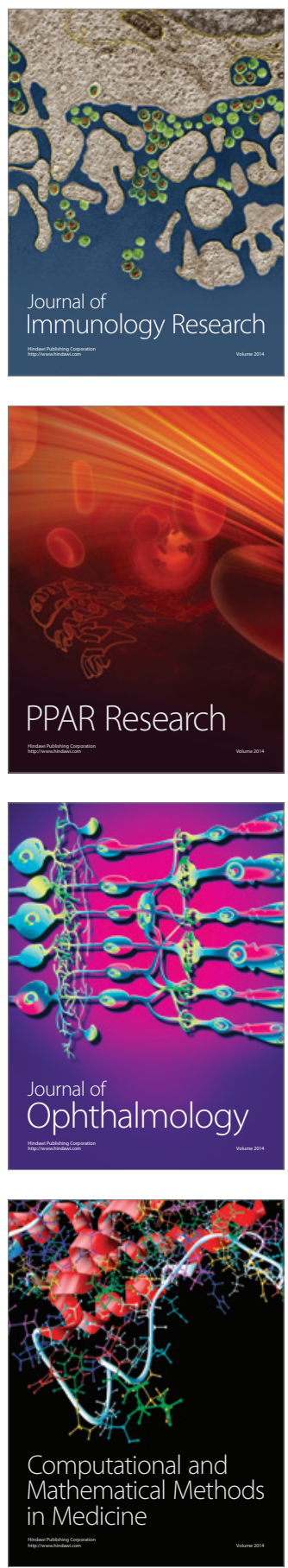

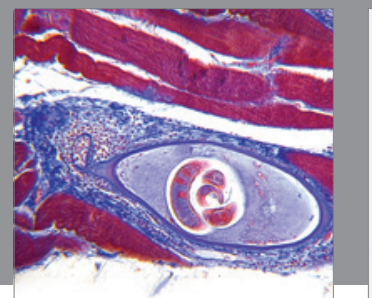

Gastroenterology

Research and Practice
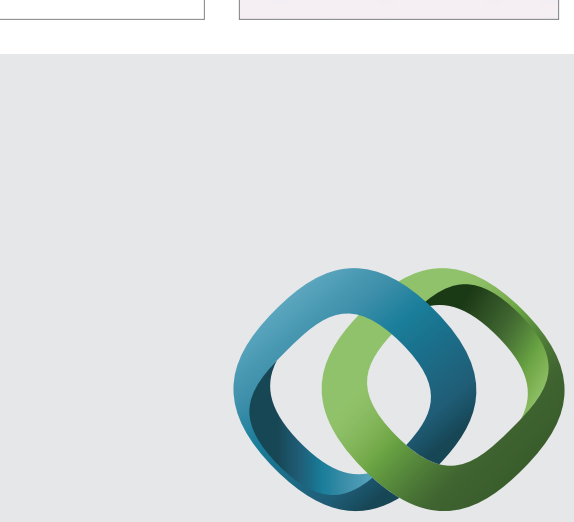

\section{Hindawi}

Submit your manuscripts at

http://www.hindawi.com
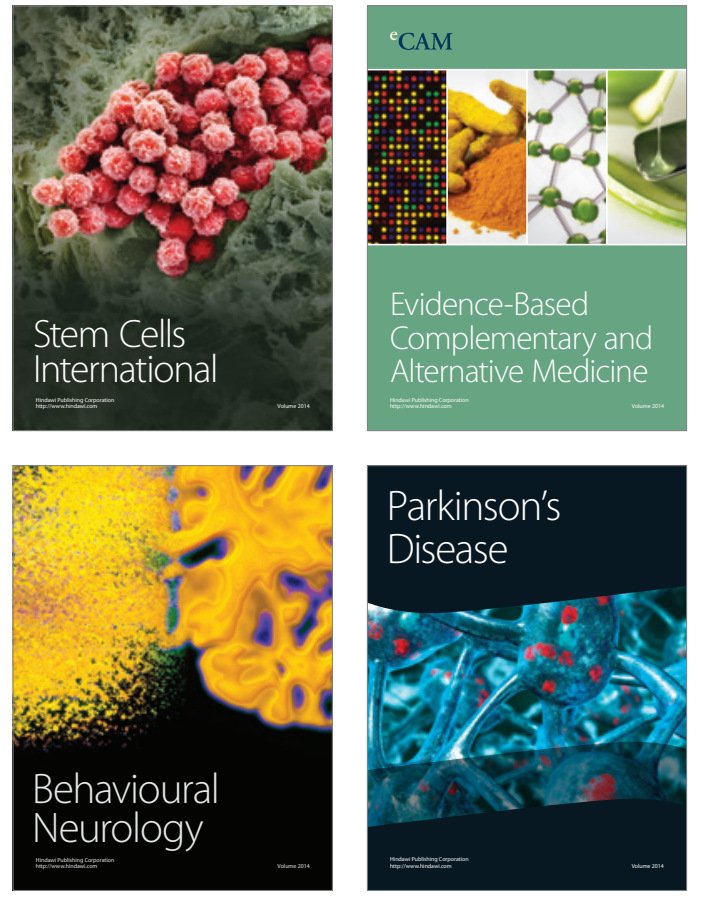
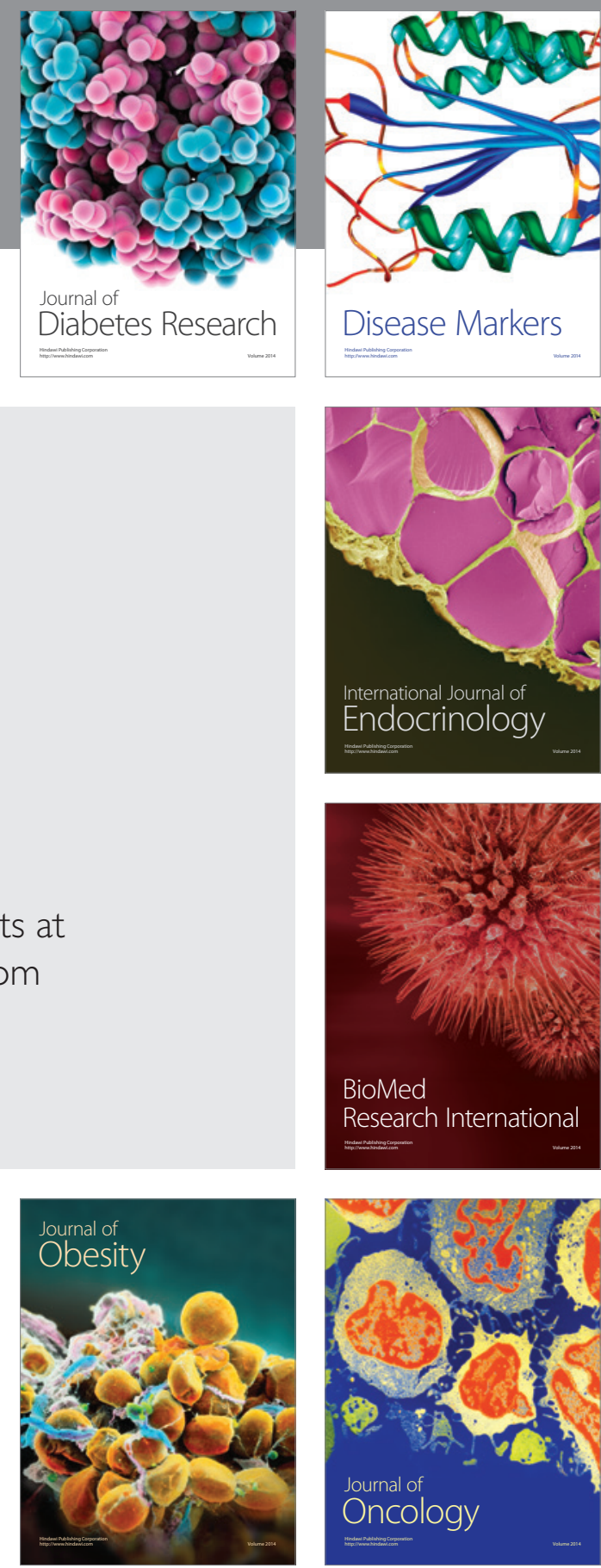

Disease Markers
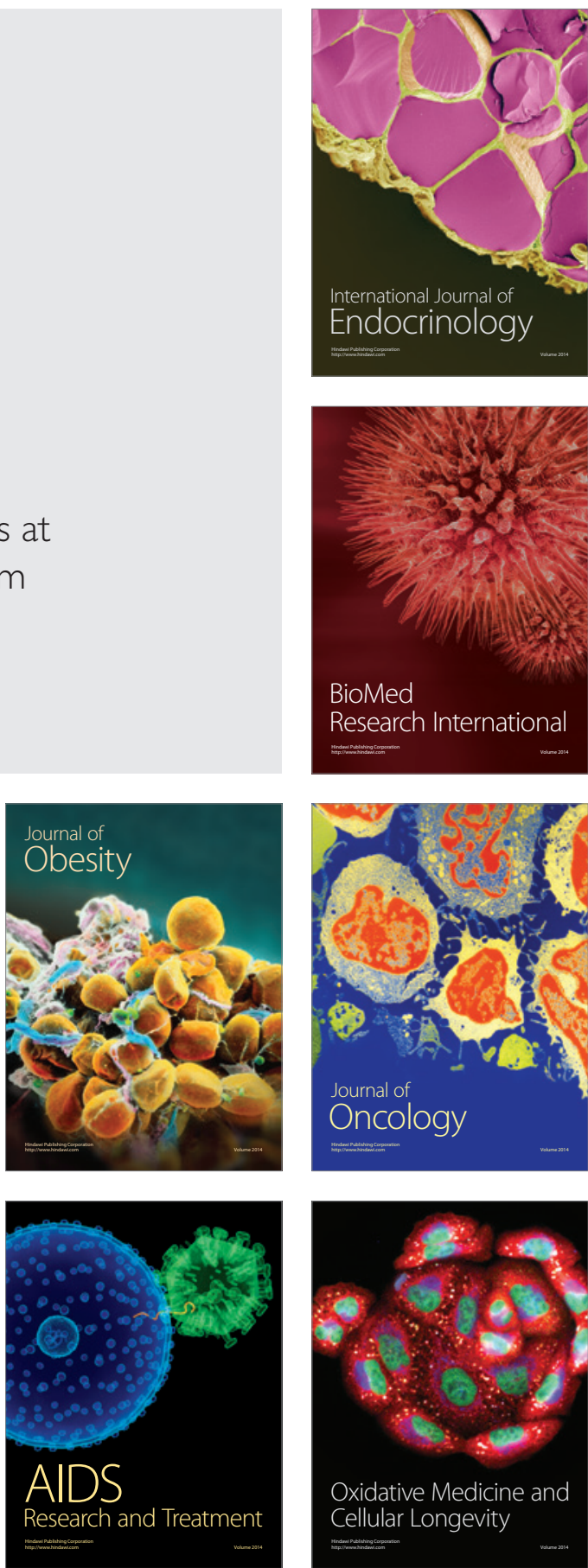